\title{
Monitoring the Short-term Variations in the Stability of the Nigerian GNSS CORS Diurnal Coordinates
}

\author{
Moses M. ${ }^{1}{ }^{*}$, Bawa S. ${ }^{1}$, Nzelibe I. U. ${ }^{2}$, Akomolafe E. A. ${ }^{1}$ and Samson B. ${ }^{1}$ \\ ${ }^{1}$ Department of Geomatics, Ahmadu Bello University, Zaria, Nigeria \\ ${ }^{2}$ Department of Surveying and Geoinformatics, Federal University of Technology Akure, Ondo State Nigeria \\ Corresponding Author: *mosesmefe@ gmail.com
}

https://doi.org/10.36263/nijest.2021.02.0313

\begin{abstract}
Positioning, based on GNSS reference network technology, is becoming a routine operation within and outside the spatial industry. The expanding user base and diverse range of applications employing this technology can impose significant expectations on the providers of reference network services. In positioning and navigation, the requirement for high accurate coordinate estimates cannot be over-emphasized. This is ensured by the provision of accurate and reliable corrections from the zero-order GNSS reference stations. It is therefore expedient to study the diurnal coordinates of such stations to guarantee reliable information for positioning and navigation applications. In this study, observation data from the Nigerian permanent GNSS continuously operating reference stations located at different states around Nigeria was processed. The hourly and diurnal (daily) coordinate solutions obtained were analysed for the purpose of monitoring the short-term stability of the network coordinates using a two-year (2012-2013) test data. The daily precise point positioning results were processed, analysed, and presented as coordinate time series using RTKPLOT. Python programming language was used to write custom modules to visualize the time series graphs at 30 seconds epochs in order to determine points and epochs where and when the condition for stability defaulted. The stations; FPNO, GEMB, and $M D G R$ were found to be most stable in the Easting component; GEMB and MDGR were the most stable in the Northing component while in the Up component the station GEMB was the most stable. The outcome of the study will assist in detecting stations that are non-operational, performing diurnal PPP processing to detect stations that are unstable, and reporting reference stations that experience sudden coordinate changes. The developed monitoring module can be implemented by the reference stations operators as an automated program for setting up an intelligent alert system to trigger a warning whenever there is unexpected coordinate breach.
\end{abstract}

Keywords: Coordinates stability, GNSS, CORS, NIGNET, Positioning, PPP

\subsection{Introduction}

Global Navigation Satellite System (GNSS) Continuously Operating Reference Station (CORS) networks are being introduced internationally to provide improved access to positioning infrastructure for a wide range of GNSS applications (Janssen and Joel, 2011). GNSS provides precise positioning and timing solutions that are unaffected by weather and without the need for a clear line of sight between ground stations. Such systems are therefore widely used in various surveying and navigation tasks. GNSS works under the basic principle that the range observations of satellites to a receiver can be used to define the coordinates of that receiver. Recently, this technology has brought about significant changes in the methods of positioning and navigation. More recently, countries are adopting continuous observation and measurements using a network of GNSS CORS as the standard. For example, Nigeria has established about 15 permanent GNSS Network (NIGNET) or CORS since 2008, which have provided the incentive for the adoption of the geocentric datum in all its geodetic activities (Ali and Samir, 2014). Such stations can conveniently replace the need for a traditional base 
station used in differential GNSS positioning, providing positional accuracy of up to $\pm 20 \mathrm{~mm}$ (Nicholas, 2010).

The Network of GNSS receivers suffers variations in coordinates as a result of errors sources like delay in the atmosphere, multipath, receiver noise, unwanted frequencies and other sources of errors. Such variations in GNSS positional time series have been studied by several scientists for quite some time, for example, (vanDam and Herring, 1994; Hatanaka et al., 2001; vanDam et al., 2001; Yuichiro and Toshiyuki, 2011; Fazilova et al., 2018; Klos et al., 2020; Qiu, 2021). The quality of the observations made by a GNSS reference station can be determined by the repeatability and long-term stability of the coordinates estimated for its antenna phase centre (Canadian Geodetic Survey, 2017). The computation of coordinates within a particular geodetic reference frame is done by integrating the reference station into an existing control network. This can be accomplished on a continuous basis at prescribed intervals by combining data from the GNSS reference with surrounding active control stations in a least-squares network adjustment.

GNSS station distribution, data quality, reliability, stability and adequacy, coordinate time series analyses and geophysical applications are among the recent research topics studied from the NIGNET CORS (Ayodele et al., 2019; Bawa et al., 2019; Ayodele et al., 2020; Okolie et al., 2020; Thomas et al., 2020). These studies have provided relevant insights regarding the scientific and operational states of the NIGNET stations. In general, the reliability, stability and positional accuracy of the network have been reported to be in order, while the adequacy and consistency of the network data have been highly deficient. While most of these studies have focused on the long-term analysis of the NIGNET data, the short-term stability and sudden instabilities experienced at the various stations remain a major challenge. With the level of accuracy expected from a CORS reference network, monitoring the short-term hourly and daily stability of the stations is expedient in providing accurate and reliable corrections to practical and operational uses of the reference stations especially for real and near real time applications. The present paper is aimed at studying the temporal variation that exists in the coordinate time series of the NIGNET CORS.

\subsection{Methodology}

\subsection{Materials}

The Office of Surveyor General of Federation (OSGOF) manages the NIGNET CORS that provide GNSS data. GNSS data collected at the CORS sites are available for download via file transfer protocol. The GNSS data collected are observation data in Receiver Independent Exchange (RINEX) format that has been compressed. RINEX files are text files that list, in text form, the L1 and L2 carrier phase and pseudocode path lengths to each satellite in view, sampled every 30 seconds. The GNSS observed data for January 01, 2012 to December 31, 2013 were obtained from the NIGNET server. Other ancillary datasets include precise clock, satellite orbit, ionospheric maps, differential code bias and antenna files provided by The National Aeronautics and Space Administration. The geographical distribution of the NIGNET CORS used in the study is shown in Figure 1. The summary of the various datasets used is presented in Table 1, while Figure 2 shows the data availability at each of the stations. Different colours were used to represent each station within the network as provided in the legend. 


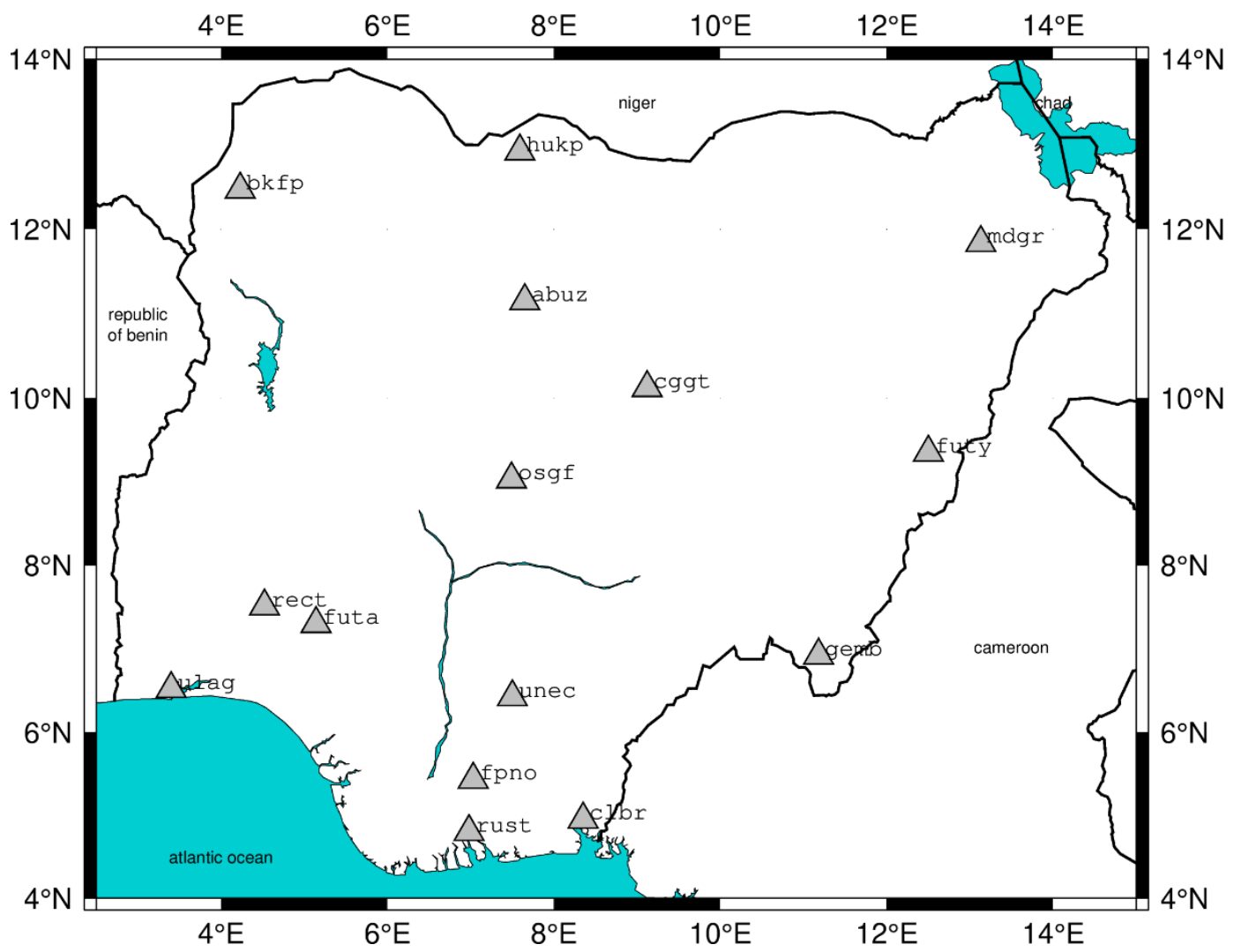

Figure 1: Geographical distribution of the NIGNET GNSS CORS

Table 1: Datasets and sources

\begin{tabular}{lllll}
\hline S/NO & DATA TYPE & FILE EXTENSION & DATA EPOCH & SOURCE \\
\hline 1 & Observation & $.12 \mathrm{O}$ and .13O & Week 1669- 1743 & www.nignet.net \\
2 & Navigation & $.12 \mathrm{n}$ and .13n & Week 1669- 1743 & www.igscb.jpl.nasa.gov/ \\
3 & Sp3 & .sp3 & Week 1669- 1743 & www.igscb.jpl.nasa.gov/ \\
4 & Antex & .atx & Week 1669- 1743 & www.igscb.jpl.nasa.gov/ \\
5 & Ionex & $.12 \mathrm{i}$ and .13i & Week 1669- 1743 & www.igscb.jpl.nasa.gov/ \\
6 & Clock & .clk & Week 1669- 1743 & www.igscb.jpl.nasa.gov/ \\
7 & DCB & .dcb & Week 1669- 1743 & www.igscb.jpl.nasa.gov/ \\
\hline
\end{tabular}

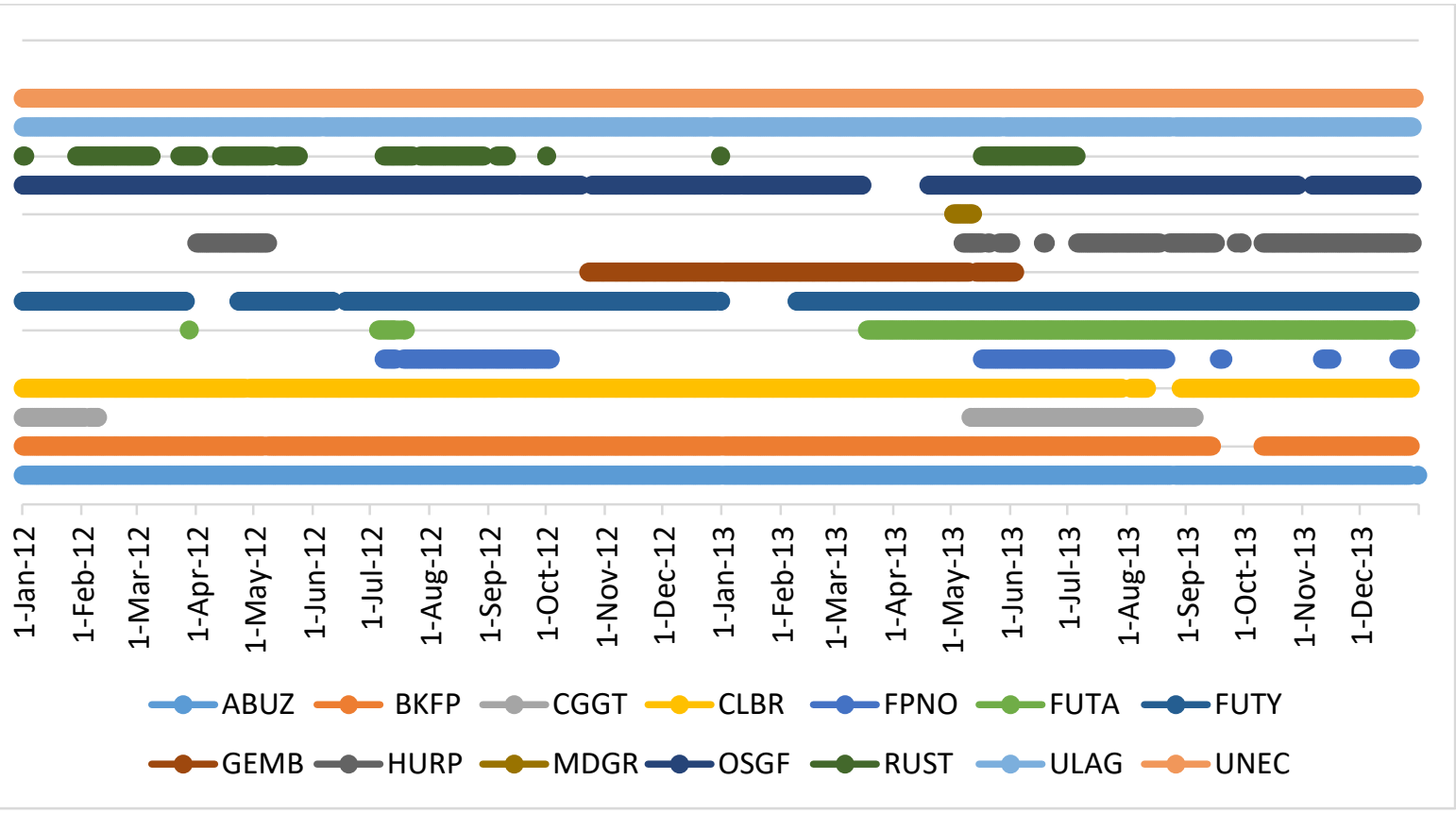

Figure 2: NIGNET GNSS CORS data availability. 


\subsection{Methods}

RTKLIB library in combination with written custom python scripts were used for the data processing and analysis. RTKLIB is a free and open-source library with pre-compiled applications for GNSS data exchange and processing. It is offered under BSD 2-clause license. RTKLIB can be considered as the most mature free open-source software for GNSS signals processing (FIG, 2019). Users are permitted to modify the source codes for commercial and non-commercial uses provided they conform to the license. The RTKLIB software which supports both single and precise point processing was used to process the GNSS observation files from each of the COR stations.

Figure 3 shows the RTKLIB PPP processing interface. The GNSS CORSs data for observation files, navigation and precise satellite orbit and clock corrections data were used as input for the Precise Point Processing (PPP). The coordinate time series were plotted using the RTKPLOT program and custom python scripts to implement the criteria for stability as provided by the Canadian Geodetic Survey. The GUI interface for the custom python program used for plotting and analysis is shown in Figure 4.

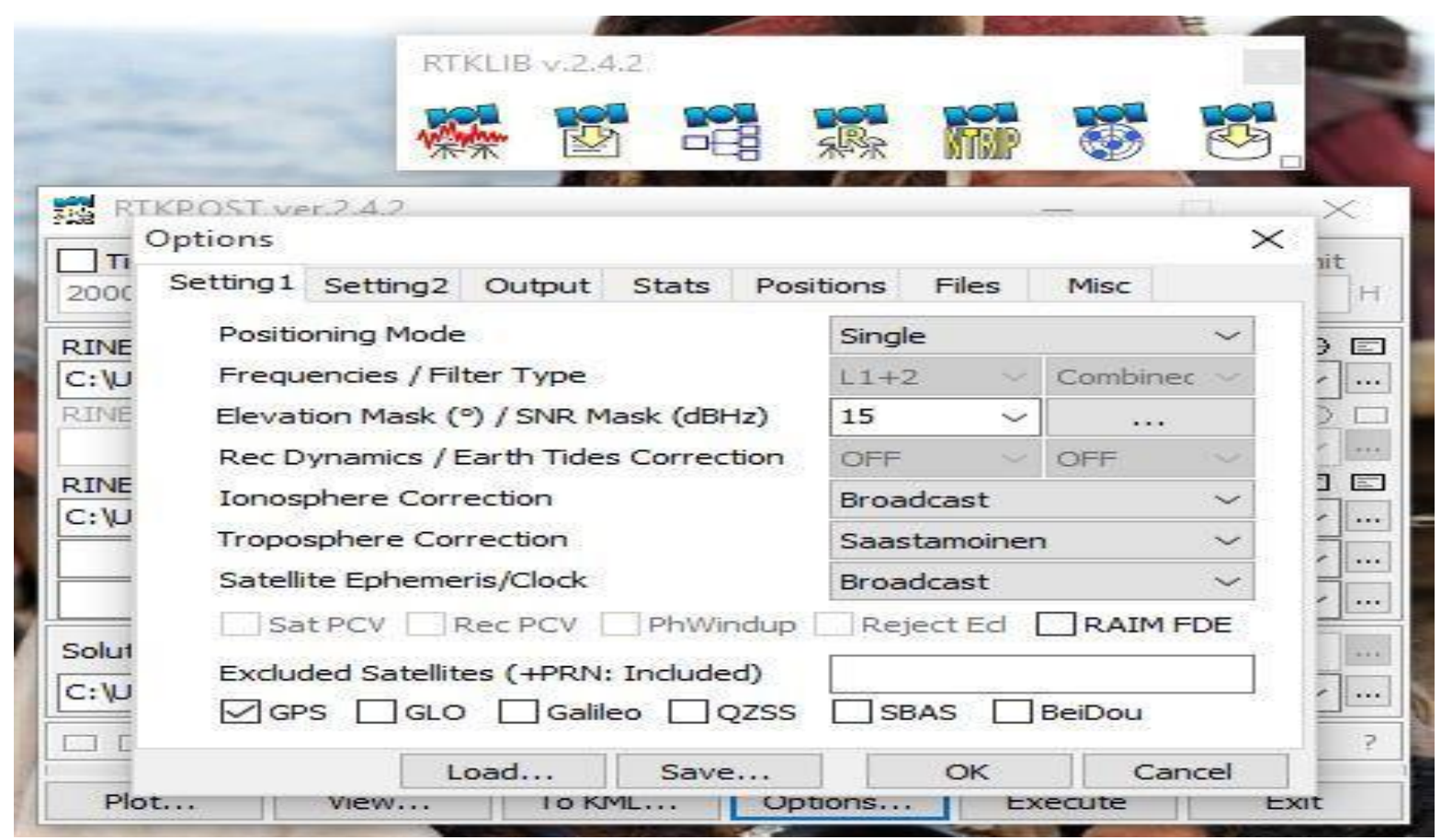

Figure 3: RTKLIB PPP processing interface. 


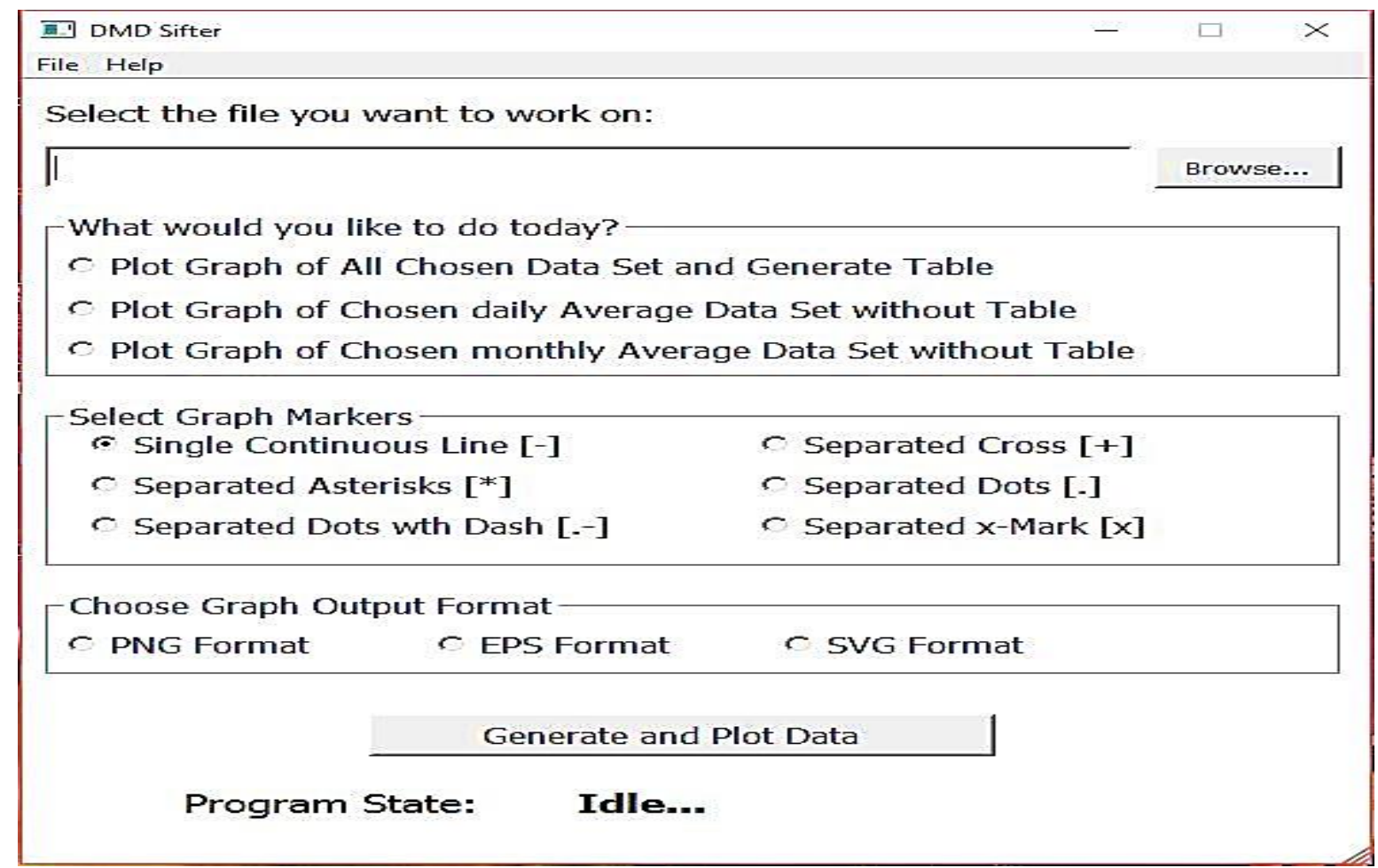

Figure 4: The GUI for custom python program for plotting and analysis

Based on the criteria for stability as provided by the Canadian Geodetic Survey, reference stations should be considered unstable if coordinate changes exceed (Canadian Geodetic Survey, 2017):

i. $\quad 5 \mathrm{~mm}$ horizontally or $10 \mathrm{~mm}$ vertically in less than 1 hour or

ii. $\quad 10 \mathrm{~mm}$ horizontally and $15 \mathrm{~mm}$ vertically in a 24 hour period

The developed program processes the reference station coordinates using both one hour time window observation and 24-hour time period to monitor where and when the above criteria occur in the recorded coordinate of the station. The station details and epoch where such occurs are then recorded by the program.

\subsection{Results and Discussion}

Time series plots of the diurnal coordinates variation for the different stations were created using the high resolution 30-seconds processed data. A sample of the time series plot at ABUZ station is shown in Figure 5. The results of the coordinate variability at each of the NIGNET CORS are presented in the following discussion. 


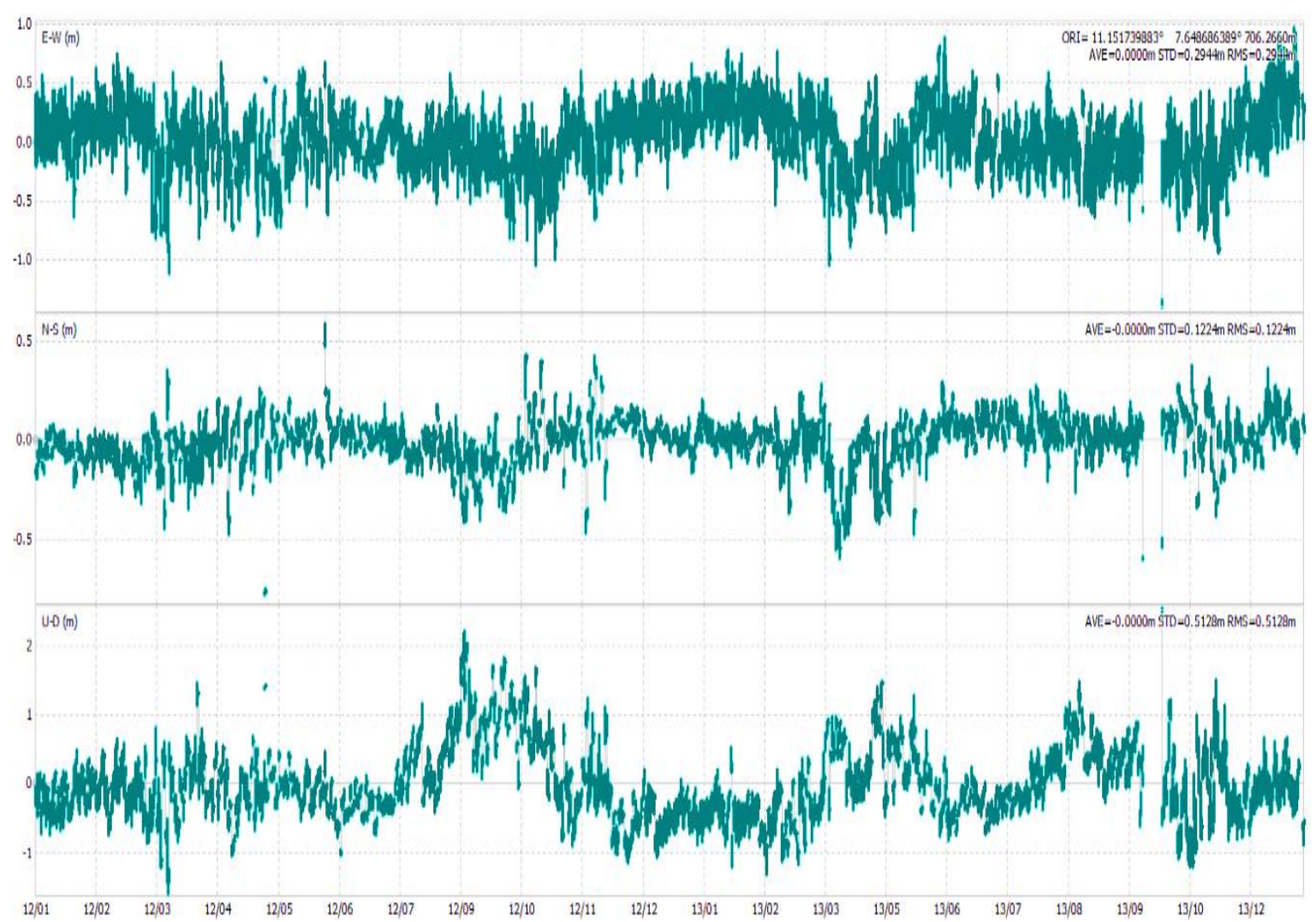

Figure 5: Time series of diurnal coordinates variation at ABUZ CORS for 2012 to 2013. The y-axis represents the coordinate variation in metres, the $\mathrm{x}$-axis represents the 30-seconds epoch of observation

The ABUZ station was observed to have variations in the months of May, June, September and November, with its highest variation ranging from $-1.8 \mathrm{~m}$ to $+1.0 \mathrm{~m}$ in the Easting component. The Northing component has a variation of $-0.7 \mathrm{~m}$ to $+0.9 \mathrm{~m}$ and $-2.8 \mathrm{~m}$ to $+2.3 \mathrm{~m}$ in the Up component. CLBR CORS has its highest variation in the months March, April, May, June, September and November with its highest variation ranging from $-1.0 \mathrm{~m}$ to $+1.8 \mathrm{~m}$ in the Easting component, $-1.8 \mathrm{~m}$ to $+1.0 \mathrm{~m}$ in the Northing component and also range between $-1.4 \mathrm{~m}$ and $+1.8 \mathrm{~m}$. BKFP was observed to show most of its variations in the months April and May, this station has outliers in the Easting, Northing and Up components ranging from $-6 m$ to $+3 m,-9 m$ to $+8 m$, and -4 to $+5 m$ respectively. For the CGGT, maximum variations were seen in the months February, May, June, July and August with its most noticeable variation ranging from $+1 \mathrm{~m}$ to $-0.4 \mathrm{~m}$ in the Easting component, $-0.8 \mathrm{~m}$ to $+0.8 \mathrm{~m}$ in the Northing, and between $-0.9 \mathrm{~m}$ to $+1.44 \mathrm{~m}$ in the Up component. The FPNO station experienced its most significant variation in the months of May, June, July and October, with its highest variations between $-1.1 \mathrm{~m}$ and $+1 \mathrm{~m}$ in the Easting component, $-0.7 \mathrm{~m}$ and $+2.5 \mathrm{~m}$ in Northing, and in the Up component it was noticed to range from $-0.9 \mathrm{~m}$ to $+4.5 \mathrm{~m}$.

Regarding the FUTA station, it was noticed that most of the high variations occur in the months May, June, July, August, and October. The highest variation was observed to be between $-1.5 \mathrm{~m}$ and $+1 \mathrm{~m}$ in the Easting, $-0.8 \mathrm{~m}$ to $+1.2 \mathrm{~m}$ in the Northing and $-1.6 \mathrm{~m}$ to $+3.2 \mathrm{~m}$ in the Up component. For FUTY, the most noticeable variations were seen in the months March, April, June, August, September, and October with its highest variation in the Easting component ranging from $-0.9 \mathrm{~m}$ to $+0.8 \mathrm{~m},-0.7 \mathrm{~m}$ to $+1.4 \mathrm{~m}$, and $-1.3 \mathrm{~m}$ to $+2.4 \mathrm{~m}$ in the Northing and Up components respectively. Analysing the GEMB CORS, it was seen that the months January, May, June, October, November, and December had the highest variations, with values ranging between $1.1 \mathrm{~m}$ to $+1 \mathrm{~m},-0.4 \mathrm{~m}$ to $+1.2 \mathrm{~m}$, and $-0.9 \mathrm{~m}$ to $+1.5 \mathrm{~m}$ in the Easting, Northing and Up components respectively. HUKP had significant variations in April, May, July, August, September and October, with ranges of $-0.9 \mathrm{~m}$ to $+1.4 \mathrm{~m}$ in the Easting, $-1.8 \mathrm{~m}$ to $+1.1 \mathrm{~m}$ in the Northing and $-2.1 \mathrm{~m}$ to $+2.8 \mathrm{~m}$ in the Up component. The Maiduguri MDGR has only few observations recorded in the month of May due to technical issues. Variations up to $-0.9 \mathrm{~m}$ and $+0.7 \mathrm{~m}$ in the Easting, $-0.3 \mathrm{~m}$ to $+0.3 \mathrm{~m}$ in the Northing, and $-1.1 \mathrm{~m}$ to $+2.9 \mathrm{~m}$ in the Up component were observed at the station. 
At OSGF station, high variations occurred in the months of June, September and November, with a range of $-3.1 \mathrm{~m}$ to $+3,-2.2 \mathrm{~m}$ to +1.9 , and $-8 \mathrm{~m}$ to $+6 \mathrm{~m}$ in the Easting, Northing and Up components respectively. The RUST CORS is seen to have its highest variations in the months of February, March, April, May, June and July, ranging from $-2.1 m$ to $+1.4 m$ in the Easting, $-1.4 m$ to $+2.4 m$ in the Northing and $-2.1 \mathrm{~m}$ to $+5 \mathrm{~m}$ in the Up component. ULAG station has its most noticeable variations in the months of May and November. The variation from the origin varies about 0 and 1 in all components. The UNEC CORS has most of its variations in the months of March, April, May, July, August, September, and November. The variations range between $-1.6 \mathrm{~m}$ to $+1.1 \mathrm{~m},-0.4 \mathrm{~m}$ to $+1.1 \mathrm{~m}$, and $-3.2 \mathrm{~m}$ to $+2.4 \mathrm{~m}$ in the Easting, Northing and Up components respectively.

\subsection{Instability in the GNSS observations based on one hour window}

Recall that reference stations should be considered unstable if coordinate changes exceed $5 \mathrm{~mm}$ horizontally or $10 \mathrm{~mm}$ vertically in less than 1 hour. The custom python script used to implement this stability condition was able to identify when and where a particular station becomes unstable based on a one hour time window. Figure 6 shows the results of counts per station in the East, North and Up components when the observations become unstable within the one-hour threshold.

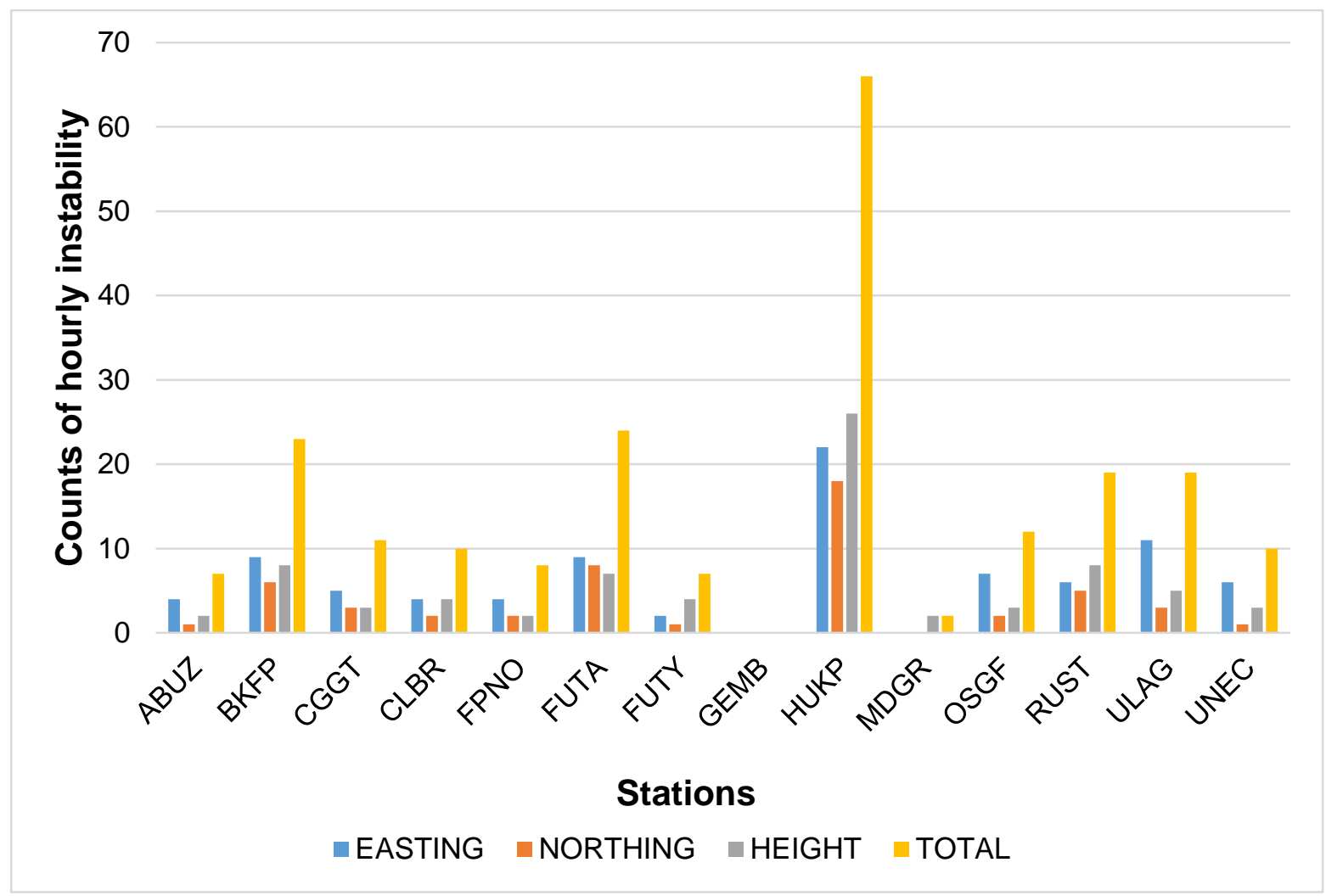

Figure 6: Counts of instability per station within the one-hour threshold

Studying each of the components individually, HUKP and ULAG had higher count of coordinates variation in the Easting exceeding the stability threshold. HUKP and FUTA had higher count in the Northing component, while HUKP, RUST, and BKFP had higher count of instability in the UP component. HUKP, FUTA, BKFP, RUST, ULAG recorded high total counts of instability in all three coordinate components. MDGR, ABUZ, FUTY, and FPNO stations had lower counts of instability within the one-hour threshold. The average counts of recorded instability in the coordinates are 6 in the Easting, 4 in the Northing and 6 in the Up component. No hourly instability was recorded at GEMB station and in the Easting component of MDGR. It should be noted however, that these stations have very limited data due to technical challenges with the stations. 


\subsection{Instability in the GNSS observations based on 24-hour time window}

With regards to a 24-hour time window, reference stations are considered to be unstable if coordinate changes exceed $10 \mathrm{~mm}$ horizontally and $15 \mathrm{~mm}$ vertically in a 24-hour period. The custom python program developed in this study was used to implement the 24-hour stability condition, reporting days where the tolerance threshold for the coordinates has been exceeded. Figure 7 shows the counts per station for days that failed the 24-hour stability condition

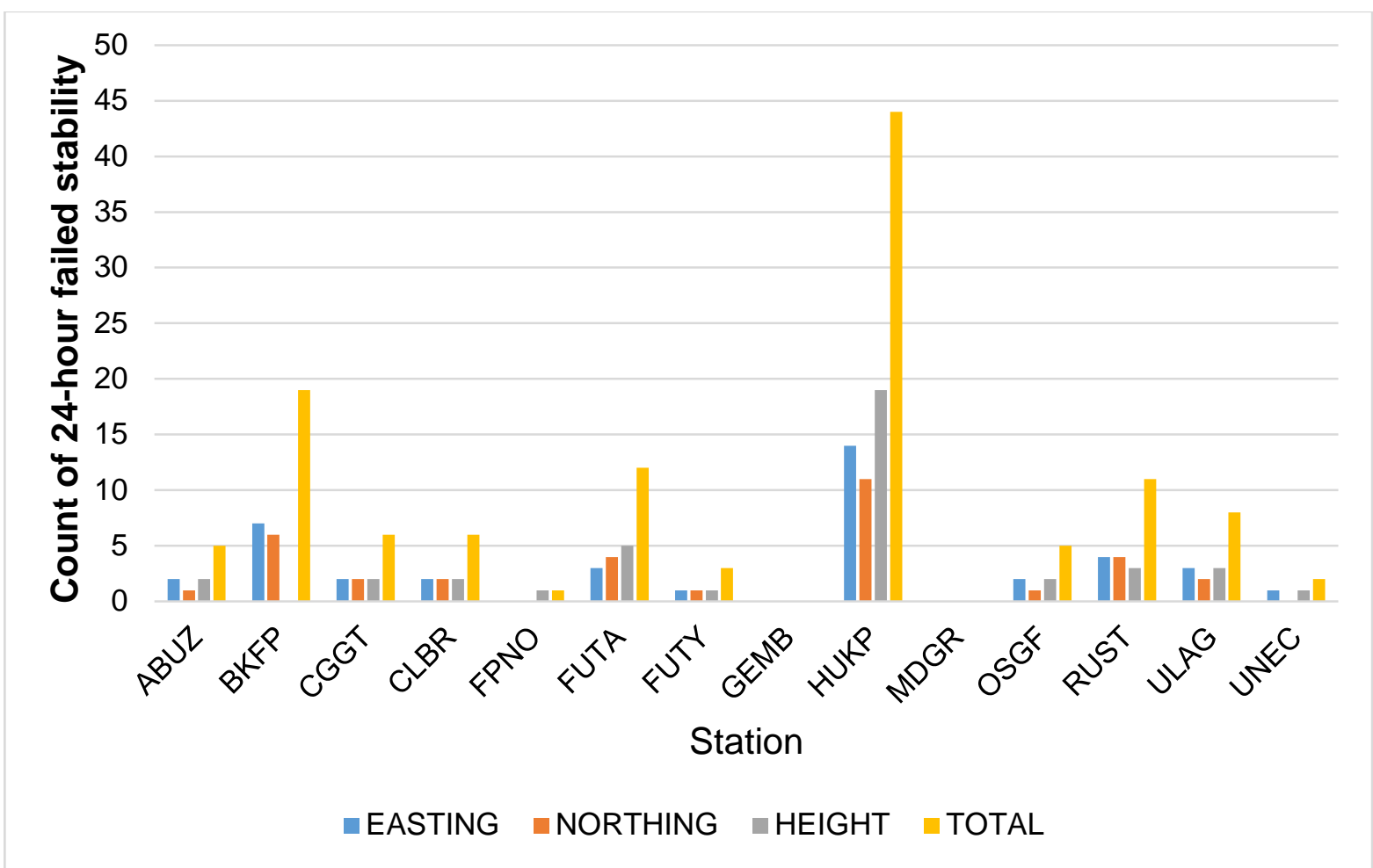

Figure 7: Counts per station for days that failed the 24-hour stability condition

HUKP station had the highest counts of days that failed the 24-hour stability condition. BKFP, FUTA and RUST also recorded higher counts of daily recorded instability are compared to the other stations. All other stations recorded an average of 2 days of instability. The variations across the NIGNET stations ranges from $2.1 \mathrm{~m}$ to $+3 \mathrm{~m},-2.2 \mathrm{~m}$ to $2.5 \mathrm{~m}$ and $-8 \mathrm{~m}$ to $+6 \mathrm{~m}$ in the Easting, Northing and Up components respectively.

In general, the results indicate that there exist more variations in the Up component than in the East and North components. This is also evident in the daily coordinate solutions. The Up component of the stations is therefore, the most affected. The variations were observed in the absence of any noticeable geophysical phenomena and therefore can be attributed to different error sources, and unwanted frequency introduced into the propagated GNSS signals. Most variations were recorded in the months April, May, July, September and November for the stations in the Northern part of the country, May, July, and August in the eastern and Southern part of the country and March, May, June, August, November and December for the Western region based on the station distribution.

\subsection{Conclusions}

The study has provided details about the short-term variability in the coordinates of the NIGNET GNSS reference stations in the country. Different stations experience different variations at different time of the year. The stations could either be considered on unstable within one-hour or 24-hour time window. It was observed that reference stations located within the same region of the country tend to experience similar coordinate variability in the same period of the year. In order to ensure accurate and reliable provision of corrections to practical and operation uses that rely on the reference stations data, the stability threshold monitoring program developed in this study can be implemented across the NIGNET server. This study thus provides the basis for developing an intelligent alert system for 
real time monitoring of CORS coordinates by reference station operators and users when noteworthy coordinate breaches occur.

\section{Acknowledgements}

The authors are grateful to the Office of the Surveyor General of the Federation (OSGOF) for the GNSS data from the NIGNET CORS. We acknowledge the use of the RTKLIB libraries in this study and also acknowledge the National Aeronautics and Space Administration (NASA) for freely providing all the satellite orbit and clock data, ionospheric maps, and the DCB files used as ancillary processing data.

\section{References}

Ali, I. and Samir, S. (2014). An Assessment of the Existing Continuously Operating. American Journal of Geographic Information System, 3(4), pp. 147-157. https://doi.org/10.5923/j.ajgis.20140304.01

Ayodele, E. G., Okolie, C. J. and Mayaki, O. A. (2019). An Assessment of the Reliability of the NIGNET Data. Nigerian Journal of Environmental Sciences and Technology, 3(1), pp. 18-29. https://doi.org/10.36263/nijest.2019.01.0097

Ayodele, E. G., Okolie, C. J., Ezeigbo, C. U. and Fajemirokun, F. A. (2020). Evaluating the stability and adequacy of nignet for the definition of nigerian geodetic reference frame. Nigerian Journal of Technological Development, 17(1), pp. 1-12. https://doi.org/10.4314/njtd.v17i1.1

Bawa, S., Ojigi, L. M., Dodo, J. D. and Lawal, K. M. (2019). Preliminary assessment of the effect of noise on velocity uncertainty on the Nigerian permanent GNSS network. Acta Geodynamica et Geomaterialia, 16(3), pp. 225-234. https://doi.org/10.13168/AGG.2019.0018

Canadian Geodetic Survey (2017). GNSS reference station installation and operation best practices. Available at: https://www.nrcan.gc.ca/sites/www.nrcan.gc.ca/ [Accessed $10 \mathrm{Jul}$. 2020].

Fazilova, D., Ehgamberdiev, S. and Kuzin, S. (2018). Application of time series modeling to a national reference frame realization. Geodesy and Geodynamics, 9(4), pp. 281-287. https://doi.org/10.1016/j.geog.2018.04.003

FIG (2019). Cost Effective Precise Positioning with GNSS. Available at: http://fig.net/resources/publications/figpub/pub74/Figpub74.pdf [Accessed 15 Aug. 2020].

Hatanaka, Y., Sawada, M., Horita, A., Kusaka, M., Johnson, J. and Rocken, C. (2001). Calibration of antenna-radome and monument-multipath effect of GEONET - Part 1: Measurement of phase characteristics. Earth, Planets and Space, 53, pp. 13-21. https://doi.org/10.1186/BF03352358

Janssen, V. and Joel, H. (2011). Assessment of Network RTK Performance using CORSnetSurvey Infrastructure and Geodesy, Land and Property Information NSW. Bathurst NSW, Australia.

Klos A., Bogusz J., Bos M.S. and Gruszczynska M. (2020). Modelling the GNSS Time Series: Different Approaches to Extract Seasonal Signals. In: Montillet JP., Bos M. (eds) Geodetic 
Time Series Analysis in Earth Sciences. Springer Geophysics. Springer, Cham. https://doi.org/10.1007/978-3-030-21718-1_7

Nicholas, G. (2010). Network CORS, who wants it? Un-published Thesis. University of. Available at: http://www.gmat.unsw.edu.au/currentstudents/ug/projects [Accesses 15 Aug. 2020].

Okolie, C. J., Ayodele, E. G., Mayaki, A. O. and Daramola, O. E. (2020). Assessing the Positional Accuracy and Adequacy of the Nigerian GNSS Reference Network. Asia-Pacific Journal of Science and Technology, 25(4), pp. 1-12.

Qiu, X. (2021). Weighted empirical mode decomposition for processing GNSS position time series with the consideration of formal errors. Acta Geodynamica et Geomaterialia, pp. 399408. https://dx.doi.org/10.13168/agg.2021.0028

Thomas, J. E., George, N. J., Ekanem, A. M. and Nathaniel, E. U. (2020). Preliminary investigation of earth tremors using total electron content: a case study in parts of Nigeria. NRIAG Journal of Astronomy and Geophysics, 9(1), pp. 220-225. https://doi.org/10.1080/20909977.2020.1723866

vanDam, T., Wahr, J. M., Milly, P., Shmakin, A. B., Blewitt, G. and Lavallee, D. (2001). Crustal displacements due to continental water loading. Geophysical Research Letters, 28(4), pp. 651-654. https://doi.org/10.1029/2000GL012120

Vandam, T. M. and Herring, T. (1994). Detection of atmospheric pressure loading using very long baseline interferometry measurements. Journal of Geophysical Research, 99, pp. 45054517.

Yuichiro, K. and Toshiyuki, T. (2011). Improvements in Accurate GPS Positioning Using Time Series Analysis. SICE Journal of Control, Measurement, and System Integration, 4(4), pp. 283-288. https://doi.org/10.9746/jcmsi.4.283. 